\title{
What is the Importance of the School Size for School Counselors?
}

\author{
Asist. Prof. Dr. Aslı Tayli \\ Mugla Sitki Kocman University, Education Faculty, Gudiance and Counseling Department \\ atayli@mu.edu
}

\section{Doi:10.5901/mjss.2014.v5n20p1800}

\section{Abstract}

This study aims to investigate the way in which the size of a school might impact on the psychological counseling services. In addition to several other features, the size of a school that is part of its structural characteristics also requires appropriate arrangements for the counseling services to be offered. As a matter of fact, there is a general principle that the guidance and psychological counseling services to be offered at school need to be customized as per the purposes and requirements of schools. This role is ascribed to psychological counselors most frequently since they are specialized in educational leadership, safe school climate and systematic change at school as a person able to assess the characteristics and potentials of students and they have the potential and power to have an impact on the social, cultural and political dynamics of schools as leaders in the social and emotional aspects of the education system. The psychological counselors are expected to perform these roles ascribed to them, to know the effects of the size of the school on the educational and psychosocial results and to make progress in preventing potential problems. There are various results with respect to the effect of the school size on the psychosocial aspects. In terms of the school size, the large, middle and small schools each have their own pros and cons as understood from the results.

\section{Introduction}

19. Since the turn of the century, the developments in the fields of social life and psychology brought the importance of psychological counselors at schools to the foreground and provided contribution to the idea of the holistic development of the academic, professional, emotional and social aspects of students ranging from pre-school to higher education (Schmidt, 1999). The task of supporting the students in educational, professional, personal and social aspects, which is expected from counseling services that are part of the education in several countries across the globe, requires a multidimensional, comprehensive assessment and a perspective that takes into account not only the person, but the entire educational system. These services which are geared towards all the students and aimed at the improvement of all students require awareness about all kinds of situations that may impact the students and their performance. Today, the rapidly emerging changes in the social life and educational outlook necessitate that the psychological counselors assume the role of being agents of chance and advocates of students as social activists in schools (Taylı, 2008).

The role of student advocacy and agency of social change expected from the counselors is recommended as an economical and effective way especially in crowded schools with a high number of students. This new role makes it necessary to focus on aspects related to the entire school and the schooling system rather than focusing on the individual, to switch from a service-providing leader to the planner, to use information for change rather than collecting information, to integrate the stakeholders of education rather than being a complementary staff member, to trigger change rather than supporting what is present and especially to demand equal educational conditions for all students (Trusty and Brown, 2005). According to this mentality, the psychological counselors are expected to be able to work with not only students, but all the parties in the educational system and to become a staff member that creates the conditions for all students to break their own records in line with their own high expectations (House and Martin, 1999).

In fulfilling this role, the psychological counselors are equipped with several other capabilities, but they are also well-suited to take the students characteristics into account, to take actions and devise solutions that are tailored to the prevailing conditions (Littrell and Peterson, 2001). The psychological counsellors at schools are educated as part of a program that gives preponderance to courses such as sociology and social psychology in order to understand the society and the effect of culture on society through lessons that would enable understanding of the general education system in addition to other skills (Baker, 2000; Muro and Kottman, 1995). Indeed, the psychological counselors at schools are also considered to have the potential and the power to impact the social, cultural and political dynamics at school (Amatea, Daniels and Bringman, 2004). This power requires the protection of student interests, alerting of the system to prevent 
harm to students, the willingness to take risks to meet the individual or group needs of students, cooperation with families and collaboration for the development and adaptation of students (Trusty and Brown, 2005).

On the other hand, it is accepted as a general principle that the guidance and psychological counseling services offered by counselors should be drafted in line with the purposes and needs of schools (Kuzgun, 2002). This means that the guidance and psychological counseling services may vary according to a number of different reasons such as the current educational step, student, teacher and governor profile, settlement area, student success, conditions of the school and the environment. It is among the student counselors' duties to make changes in the schools services to be offered and to make changes that balance the needs of the students depending on the mentioned variables, It seems indispensable to progress in line with a plan adapted to this situation for the services to be offered by taking into account the number of students, teachers and staff members at school in addition to several other factors.

This study aims to tackle the reason why it is important to know the potential effects of the school size, which is one of the important structural features of a school. By this means, it will emphasize the importance of the size of school to be taken into account in the assessments, decisions and practices of school counselors related to the school counseling services. This study will dwell upon the results educational and psychosocial results of the school size on the students, then it will deal with the way in which these results may lead the way in the adjustment of counseling services at school. The study is a field literature review conducted for the mentioned purposes.

\subsection{The Effect of the School Size on the Educational and Psychosocial Results at Schools}

The research related to school size generally includes studies focused on the academic success and educational results (Akkalkan, 2009; Barnett, Glass, Snowdon and Stringer, 2002; Coladarci, 2006; Weiss, Carolan, \& Baker- Smith, 2010; Werblow and Duesbery, 2009). These are studies that show that more positive results are received in small or mediumsize schools whereas there probability for negative results is higher the larger the schools are. Various studies demonstrated that success in math was inversely proportional with the school size (Weiss, Carolan, and Baker- Smith, 2010; Werblow and Duesbery, 2009), large schools scored low in exams on math, reading, writing and science (Stewart, 2009) and that larger schools scored lower in educational results such as "best application" and "efficiency" as compared to smaller schools (Barnett, Glass, Snowdon and Stringer, 2002). On the other hand, there are also studies that demonstrate that the large schools create a more competitive environment with their dynamism, thereby bringing about higher academic success (Leithwood and Jantzi, 2009; Riha, Slate and Martinez-Garcia, 2013). Similarly, a study conducted in Turkey during which the opinions of school headmasters of 20 schools in total with 10 large and 10 small, large schools are more successful than small schools in terms of success in examinations for entering the high school and passing the class with a certificate of success. The headmasters explained that the greatest advantage of large schools with respect to the academic success of students was that there was a more competitive environment at school since the number of successful students and the variety of differences were higher (Akkalkan, 2009).

On the other hand, very small schools are not desirable due to a less stimulating environment, lower competition and an insufficiently dynamic structure (Lee, 2000:340) in spite of the study results that demonstrate the advantage of small schools for academic achievement (Crosnoe, Kirkpatrick-Johnson and Elder, 2004; Lee, 2000:340; Weiss, Carolan, and Baker- Smith, 2010; Werblow and Duesbery, 2009). However, it was found that small schools were more advantageous especially for the children of families with low socio-economic standing (SES) and children of families in disadvantaged conditions. This situation is interpreted as the weakening of the strong effect between SES and academic achievement and reduction of the possibility of failure (Coladarci, 2006).

While the effect of school size on academic achievement was frequently investigated, its effect on the psychosocial dimension was studied to a lesser extent. For example, the following assumption is maintained in relation to the effects of small schools on psycho-social dimension: the students would demonstrate better performance when they are supervised and protected by adults, the students would be in contact with mode adults in small schools, which would mean further individualization of the education (Strike, 2008). It is assumed that there would be more isolation, alienation and frustration in large schools due to the nature of the social relations at school. Those who hold the view that the students would have a higher possibility of feeling lonely and isolated in large schools support the opinion that the students would be surrounded by more unknown people in crowded schools. It is defended that the school headmasters in large schools would also be more specialized due to a high number of administrative tasks, but they would head more towards administrative tasks in a distant way from the students, thereby causing the students to feel more isolated and ordinary. It is accepted that the large schools would also trigger some changes in the characteristics of teachers. In large schools, teachers turn over time into individuals who are more specialized in specific subject matters. This situation cause them to focus more on their areas of specialization, dedicate less time to students, communicate less with students and to risk not 
noticing the students' problems in due time (Leung and Ferris, 2008).

Studies in the field of social psychology often deal with the negative effect of a crowded environment. These studies conducted on animals showed that the mice that had become higher in number and had less space for themselves had increased adrenalin levels, exhibited more aggressive behavior that even reached the point of death and caused results such as not showing any attention to sexuality or newborns (Akyıldı, 1994). Similarly, it was observed that being in a crowded environment triggered an intensity of stimuli on the individuals, resulted in tiredness and exhaustion, causing the persons to become more reserved and that it even increased anxiety and competition in certain cases causing them to adopt a possessive attitude to their kin and an exclusionist attitude to their competitors (Akyוldı, 1994). It might be expected that crowded schools also result in similar environments with respect to the psycho-social conditions. For example, a study by Ripski and Gregory (2009) showed that schools that were larger than normal was perceived by students as being less safe and less friendly. The researcher commented on this situation as follows: large schools had an increased possibility of causing rage and frustration in student due to their structural characteristics, which caused violence to erupt more often. In such large schools, the students perceived the school as being an unfair, hostile and victimizing place and they reported a lower level of attachment to school. These students with a negative perception of the climate in school are also less successful in terms of academic achievement. The same study demonstrated that having a broken family, friends with criminal behaviors and attending low-quality school increased the rate of violence by $13 \%$ to $23 \%$. However, the negative effect of the school size is significant even when these variables are under control (Ripski and Gregory, 2009).

A correlation has also been found between the school size and family as well as student participation. For example, the larger the school is, the lower the possibility of families to take part in school process and voluntary tasks at school are. However, it is expressed that this result has a certain statistical significance, yet it has a low level of effect (Walsh, 2010). In addition to family participation, student participation was also studied. Indeed, the possibility of large schools to have a student assembly is higher $(91 \%)$ as compared to small schools. Similarly, the possibility of schoolsponsored community service is higher for large schools (91\%) as compared to small schools (85\%). However, very small schools (fewer than 300 students) offer more student participation and a higher possibility of community service whereas schools with 1800 and more students somehow have a lower rate of participation and voluntary service per student. Similarly, it was observed that the school size was inversely proportional with the level of student attachment to school, satisfaction with the student-teacher interaction and participation in extra-curricular activities at school (Walsh, 2010).

\subsection{School Size and Psychological Counseling Services at Schools}

It is accepted that school size would have a direct or indirect effect on the educational and psychosocial results of the education system. The discussions are focused on the specific results brought about by specific schools sizes and the identification of an ideal school size. The studies generally accept that very large or very small schools have some challenges of their own nature. For example, there are results indicating that numbers of students such as 400-900 or $500-1000$ are more advantageous in terms of various positive results (Akkalkan, 2009; Bakioğlu and Geyin, 2009; Tayll, 2013). On the other hand, the classification of schools as large or small schools also varies as per the educational step. For example, classifications exist for high schools such as small (1-500), relatively small (501-999), relatively large (1000-1599) and large schools (1600 - 2499) (Weiss, Carolan, and Baker- Smith, 2010). As for the pre-school and primary school levels, the classification includes small schools (1-275), middle-small size (276, 400), mid-size (401-600), middle-large size (601- 800) large (800 and above) schools (Ready and Lee, 1997). Furthermore, another important variable for determining the ideal size of a school is the set of criteria that are taken as basis for a particular educational step. For example, studies on the high school and secondary school levels discuss more often the school size whereas the classroom size seems to be a more important variable for the pre-school and primary school (Ready and Lee, 2006/2007).

For the psychological counselors at schools, knowing the size of the school they work at with respect to the number of students and staff members as well as the pros and cons associated with that would enable them to make appropriate adjustments in the services they offer. As for the advantages and disadvantages of small and large schools, various discussions are maintained on this subject. For example, it is mentioned that large schools offer more resources and physical amenities, hence a richer stimulating environment to students (Harris, 2006/2007), therefore they would create an environment of stronger competition and enhance results of success (Akkalkan, 2009). On the other hand, it is defended that large schools would have a relatively more official, more bureaucratic functioning; there would be a stricter line between students, teachers and administrators as a result of which the teachers would have less liberty in going 
outside the borders of the pre-determined functioning. Similarly, it is accepted that the teachers in such schools would be less willing to take responsibilities in teaching and that the academic achievement would be marked by a lower success rate. At the same time, it is explained that the relationship and interaction between students and teachers would be less individualized (Lee, 2000; 340). As for the small schools, it is defended that the children would feel safer there, they would have a lower risk of being lost in the crowd and that the teachers would have the chance to teach lessons in a way that is more compliant with the curriculum. The same outlook is also maintained for small classrooms and it is defended that the children's attention would be less divided, they would be less distracted, therefore, they would receive more attention and a more individualized education service in such an environment (Harris, 2007-2007). The reason why small classrooms are shown as advantageous is as follows: it is assumed that they enable teachers and students to know and interact with one another, the inter-personal climate at school would be better and the academic achievement as well as other results would therefore be positive (Crosnoe, Kirkpatrick-Johnson and Elder, 2004

Some authors hold the view that the role of school counselors is to provide educational leadership as person who is able to assess the developmental characteristics and potential of students. This role is ascribed to the counselor due to their positions of providing support for the students, families, teachers and the school system in general. The connection of counselors with the other psychological organizations in the society in addition to their organizational roles at school, their stewardship role in programs such as student leadership, peer facilitation and character education make it easier for school counselors to emerge as the leaders in the emotional and social dimensions of the educational system (Dollarhide and Saginak, 2003: 203-216). Similarly, school counselors are considered to be the specialists who hold the most critical position for a safe school climate and systemic change at school (Hernandez and Seem, 2004). In a similar vein, the responsibility to develop and implement peer-based programs such as peer tutoring, peer mediation, peer education, peer consulting, which are geared towards enabling students to help and support other students, is also first and foremost on the part of psychological counselors at schools (Pearson and Nicholson, 2000; Thompson, 1996).

The task of supporting the healthy development of students at the primary and secondary school and their families through education programs is expected most often from psychological counselors (Amatea, Daniels and Bringman, 2004). As a matter of fact, it is accepted that psychological counselors at school assume the position of leaders and advocates as members of the training team at school, who exert efforts for the realization of academic success and education targets and strengthening the family-school collaboration. This role is ascribed to psychological counselors at schools on account of their potential and power to have an impact on the social, cultural and political dynamics of school (Amatea, Daniels and Bringman, 2004). Similarly, psychological counselors at schools in all educational steps also acknowledge their important position for the collaboration among schools, families and society (Bryan and HolcombMcCoy, 2004).

All these statements bring the leadership of school counselors to the foreground. Considering that this is the case, psychological counselors at schools need to assess all kinds of structural and human factors pertaining to the school that may affect the entire school and all students in a way similar to school administrators. Additionally, psychological counselors at schools need to know the general dynamics and effects of large, medium and small schools very well. This means that precautions are needed to raise the awareness of teachers and school administration and to enhance attachment to school for a school climate that is embracing and positive for all students given that large schools are perceived to be less safe, more hostile and less fair (Ripski \& Gregory, 2009). Based on the same mentality, efforts should be maintained and collaboration should be ensured with the elements around the school in order to take precautions to reduce violence and gang-like clusters among students given that the classroom size and consequently school size are inversely proportional with the control by teachers and the likelihood of students to form groups and ganglike clusters (Yaman, 2006).

Large schools create a relatively more cramped and crowded environment due to the high number of students. It is also known that crowds have the effect of raising the anxiety levels of individuals. This translates into the possibility to behave in a more aggressive way. As a matter of fact, more disciplinary actions and more accidents have been reported in large schools (Klein and Cornell, 2010). A study by Taylı (2013) shows that medium-size schools are the types of schools where bullying behaviors are observed least frequently. Crowded/very crowded schools more often tend to be backdrops for alienation and loss of identity; therefore, students may exhibit behaviors such as bullying or acts that are not becoming to them more often due this loss of identity (Leung and Ferris, 2008). This fact should be acknowledged and efforts ought to be made for students to take responsibility for their actions and for personal control to be exerted. It is known that especially programs such as William Glasser's Reality Therapy ensure enhanced levels of responsibility and personal control (Kim, 2002, Kim, 2006). The theory which is also known as the Choice Theory and Control Theory may aid in reversing the correlation between crowded schools and loss of identity.

On the other hand, it is considered that very small schools would provide a much less stimulating environment in 
both social and intellectual sense for especially the adolescents and higher age groups (Lee, 200:340). It is considered that schools with very few students would have a less competitive atmosphere, hence lower achievement level (Akkalkan, 2009) and that their curricula would more often have practices that do not fit the educational expectations of students and that the students might be excluded in some cases since the social standing of their family is known (Lay, 2007). This means that schools with a reasonable size (ex. 500-1000) are perceived to be more positive especially by older age groups as compared to schools with 500 and fewer students. A psychological counselor should be able to plan horizonexpanding experiences so that students do not bear the brunt of having a limited number of stimulants only because they are brought up in a calmer environment and attending a small school and they can be prepared for a successful future. For example, secondary school students living in areas where there is a university or specific university departments scored high on the career development test as compared to other students (Can, 2012). Even the presence of a university in the place of residence contributes to a stimulating environment for students. The same study also found that the career development scores of students in rural areas were lower than students in urban centers, students with highly educated parents than those with lowly educated parents, those with low socio-economic standing than those with a high socio-economic standing, students planning to choose a vocational high school as compared to those planning to choose an academic high school requiring higher grades (Can, 2012). Small schools are effective when the low number of students is limited intentionally and these advantages of them are taken cognizance of. For that reason, the desired success may not be achieved in small schools based in rural areas that have few students not necessarily out of a concern to keep the number low intentionally (Ready \& Lee, 2006/2007). As understood from the results achieved in this study, factors such as low education level, low socio-economic level, living in a rural area and not having a university in a rural area combine to bring about a lower awareness of career, a lower expectation from future and a lower level of preparedness. In this case, the psychological counselor, a person who knows the conditions of students and their potential results, should try to widen the horizons of students through family education programs, visits to universities, presentations of successful examples or invitation of role model guests to the school.

Psychological counselors at schools should know that the results for large, medium-size and small schools may not always be universal facts applicable at all times and for all cultures. For example, schools that are in rural areas and far from urban centers as well as small schools in Texas, USA are found more advantageous (Stewart, 2009) whereas an assessment of schools in rural and urban areas in Estonia found the large schools and schools in (Aidla and Vadi, 2007). It should be kept in mind that different results are possible due to variables such as the education system, cultural structure and other characteristics of countries. Similarly, it should be known that it is affected by a very large set of variables including the school size. Based on the same mentality, even though there are research results indicating that small schools are advantageous, it will not be possible to achieve positive results by deciding on a small student population for schools and transferring students to that school. In reality, the number of students at a school per se does not bring about positive results. However, it seems that it facilitates the emergence of some results thanks to its characteristics (Weiss, Carolan, and Baker- Smith, 2010).

\section{Conclusion}

In conclusion; school counselors are expected to create a supportive environment for all students in the school environment and to encourage the students to optimism and being hopeful. For this purpose, there is further need for holistic assessments by counselors such as those focused on the school climate and the structural characteristics of schools in terms of their effect on students. In that respect, it is especially important to know that schools of every size whether medium or small have different advantages and disadvantages with respect to educational and psychosocial results and to make appropriate arrangements be made in the services to be offered.

As for the effect of the school size on educational and psycho-social dimensions, various results are available. While there are studies suggesting that large schools would offer a less supporting environment for students and there is the possibility to have lower success rate, there are also other researchers and studies defending that they would offer a more competitive and stimulating environment thanks to the richness of resources. In this case, the nature of large schools that enable a more dynamic and customized curriculum as well as extra-curricular activities should be maintained while caution should be exercised with respect to the possibility of students to feel lonelier, more isolated and become subject to bullying. Small schools, on the other hand, may offer a more restrictive and monotone environment in certain situations in spite of their psycho-social and educational advantages. Given the fact that very small schools may provide an environment with much fewer stimuli in both social and intellectual terms, it is especially that psychological counselors engage in collaboration with universities and science institutions in the country to increase the academic achievement level and to meet the intellectual requirements of students and to exert their efforts for horizon-expanding experience and 
opportunities for these students, which is especially important for the students who are in the adolescence period.

On the other hand, it is accepted that the psychological counselors at schools have the potential and power to have an impact on the social, cultural and political dynamics of a school. This power requires maintaining the interests of students, triggering the system to prevent any harm to students, collaborating with families and engaging in cooperation with all of the stakeholders in the educational system for the development and adaptation of students. This situation brings to the fore the role of psychological counselors at school as social activists, agents of change and student advocates. This role necessitates arrangements that take into account the school size, a structural feature, in order to achieve a systemic change.

\section{References}

Akkalkan, H. (2009). Correlation between the School Size and the Academic Achievement, School Attendance and Discipline of Students in the Çankaya District, City of Ankara. Ankara: Ankara University, Institute for Educational Sciences, Unpublished Master Thesis.

Akyıldız, (1994).Crowded educational system and behavioral results. 1. Educational Science Congress, volume 2, 28-30 April 1994: Adana

Aidla, A. \& Vadi, M. (2007). Relationships Between Organizational Culture And Performans in Estonian Schools With Regard To Their Size And Location. Baltic Journal Of Economics 7(1), 3-11.

Amatea, E. S., Daniels, H. ve Bringman, N. (2004). Strengthening Counselor -Teacher- Family Connections: The Family- School Collaborative Counseling Project. Professional School Counseling, 8 (1), 47, 58.

Baker, S.B. (2000). School Counseling for he Twenty-First Century. Third Edition. New Jersey: Pearson Edocation

Bakioğlu, A. \& Geyin, Ç. (2009). What does school size do: Safety perceptions of educators and students. US-China Education ReviewOct. 2009, Volume 6, No.10 (Serial No.59)1-8.

Barnett, R.R., Glass, J.C., Snowdon, R.I. \& Stringer, K.S. (2002). Size, Performans And Effectiveness: Cost-Constrained Measures Of Best- Practice Performans And Secondary School Size. Education Economics, 10(3), 291-311.

Bryan, J. \& Holcomb-McCoy, C. (2004). School Counselors' Perceptions of Their Involvement in School-Family-Community Partnerships. Professional School Counseling, 7(3), 162-171.

Can, A. (2012). An Examination of The Career Developments Of Primary School Students In The Second Stage. Mugla: Ankara Sıtkı Koçman University, Educational Sciences Institute, Unpublished Master Thesis.

Crosneo, R., Kirkpatrick- Johnson, M.\& Elder, G.H. (2004). School Size And The Interpersonal Side of Education: An Examination Of Race/Ethnicity And Orgnizational Context. Social Science Quarterly, 85(5), 1259-1274.

Coladarci, T. (2006). School Size, Student Achievement, And The "Power Rating" Of Powerty: Substantive Finding Or Statistical Artifact?. Education Policy Analysis Archives, 14 (28), 1-23.

Dollarhide \& Saginak, 2003: 203-216). Baker, S.B. (2000). School Counseling for he Twenty-First Century. Third Edition. New Jersey: Pearson Edocation

Harris, D.N. (2006/2007). Class Size and School Size: Taking the Trade- Off Seriously. Brookings Papers On Education Policy, 137-161.

Hernandez., Thomas J., Seem., Susan R. (2004). A Safe School climate: A Systemic Approach and the School Counselor. Professioanal School Counseling, 7 (4), 256-262.

House, P.N. \& Martin, P.J. (1999). Advocting for Beter Futures for all Students: A New Vision for School Counselors. Education, 119 (2), $284-290$

Kim, K. H. (2002).The Effect of Reality Therapy Program on The Responsibility For Elementary School Children In Korea. International Journal of Reality Therapy, 22(1), 30-33.

Kim, J. U. (2006). The Effect of A Bulling Prevention Program on Responsibility And Victimization Of Bullied Children In Korea. International Journal of Reality Therapy,26 (1), 4-8.

Kuzgun, Y. (2002). Guidance and Counseling Psychology. 8. Edition. Ankara. OSYM Publishing.

Lay, J.C. (2007). Smaller isn't Always Beter: School Size And School Participation Among Young People. Social Science Quarterly, 88 (3), $790-815$.

Lee, V.E. (2000). School Size And The Organization Of Secondary Schools İn. Handbook Of The Sociology Of Education. M.T. Hallinan (Edit.). New York: Kluwer Academic/Plenum Publishers.

Leung, A. \& Ferris, J. S. (2008). School Size and Youth Voilence. Journal of Economic Behavior \& Organisation, 65, 318-333.

Leithwood, K., \& Jantzi, D. (2009). A review of empirical evidence about school size effects: A policy perspective. Review of Educational Research, 79(1), 464-490.

Littrell, J.M. \& Peterson, J.S. (2001). Transforming the School Culture: A Model Based on an Exemplary Counselor. Profesional School Counseling, 4, (5), 310-320.

Muro, J.J. \& Kottman, T. (1995). Guidance and Counseling in the Elementary and Middle Schools: A Practical Approach. USA: Brown \& Benchmark.

Pearson, Q. \& Nicholson, J. (2000). Comprehensive Character Education in the Elementary School: Strategies for administrators, Teachers and Counselors. Journal of Humanistic Counseling, Education \& Development, 38 (4), 243- 251.

Thompson, S.M. (1996). Peer Mediation: A. Peaceful Solution. The School Counselor, 44, 151-155. 
Thursty, J. \& Brown, D. (2005). Advocacy Competencies for Professional School Counselors. Profesional School Counseling, 8 (3), 259 265.

Ready, D.D. \& Lee, V.E. (2006/2007). Optimal Context Size İn Elementary Schools: Disentangling The Effect Of Class Size And School Size. Brookings Papers On Education Policy. 99-136.

Riha, Slate \& Martinez-Garcia (2013). What We Know About Mıddle School Size And Student Performance: A ReviewOf The Literature. Journal of Education Research, 7 (3), 206-229.

Ripski, M.B. \& Gregory, A. (2009). Unfair, Unsafe And Unwelcome: Do High School Students' Perceptions Of Unfairness, Hostality, And Victimization In School Predict Engagement And Achivement?. Journal Of School

Stewart, L. (2009). Achievement Differences Between Large And Small School in Texas. The Rural Educator, 30(2), 20-28.

Schmidth, J. J. (1999). Counseling in Schools: Essential Services and Comprehensive Programs, Third Edition, Boston; A Viacom Company.

Strike, K.A. (2008). Small Schools: Size or Community. American Journal of Education,114, 169-190.

Taylı, A. (2008). Psychological counselors as student advocates and agents of change at schools. Turkish Psychological Counseling and Guidance Newsletter, 16 (2), 40-48.

Taylı A. (2013). School sıze as a predıctor of bullyıng. Internatıonal Journal of Academıc Research, 5(5), 124-130.

Walsh, P. (2010). Is Parental Involment Lower At Larger Schools?. Edonomics Of Education Review, 29, 959-970.

Weiss, C.C., Carolan, B.V. \& Baker- Smith , E.C.(2010). Big School, Small School: (Re)Testing Assumptions About High School Size, School Angagement And Mathematics Achievement. Journal Of Youth Adolescence, 39: 163-176.

Werblow, J. \& Duesbery, L. (2009). The İmpact Of High School Size An Math Achievement And Dropout Rate. The High School Journal. Feb/Mar., 14-23.

Yaman, E. (2006). An Aspect of the Problems in the Educational System: Large Classrooms and Classroom Management. Turkish Journal of Educational Sciences, 4 (3), 261- 264. 